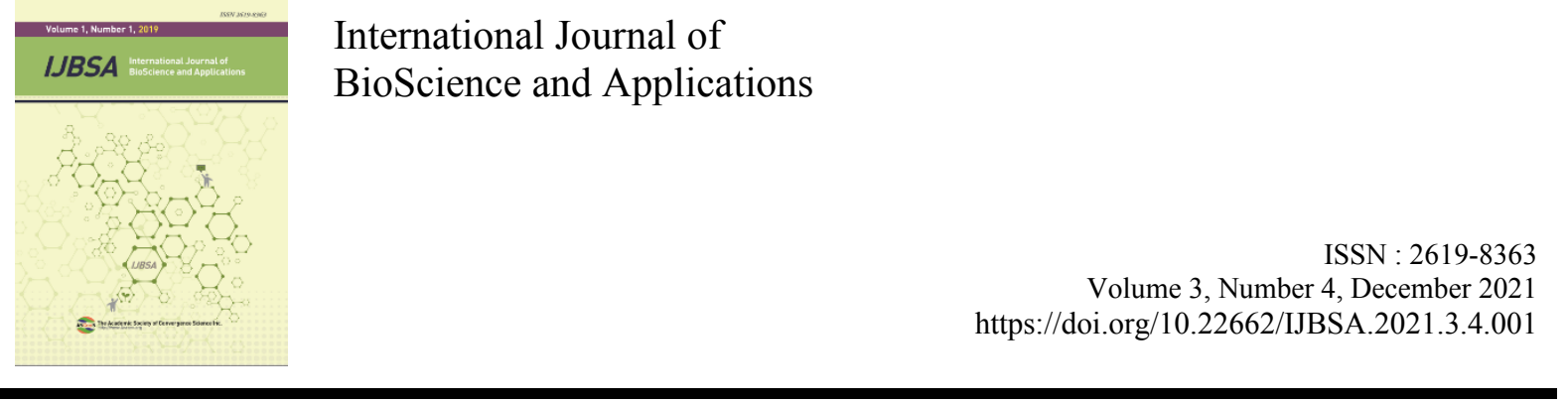

\title{
Pro-inflammatory Cytokine Production Inhibitory Effects of Burdock extract
}

\author{
Jeong-Sook Park \\ Department of Nursing, Nambu University, Gwangju, Republic of Korea
}

\begin{abstract}
Background/Objectives: This study aims to demonstrate pro-inflammatory cytokine production inhibitory effects using Burdock extract. In addition, the basic mechanism of the anti-inflammatory mechanism of burdock is to be studied Methods/Statistical analysis: Thus, This paper was carried out to see the production of NO and pro-inflammatory cytokine ,TNF- $\alpha$, IL- 6 and IL-8 using the macrophages of LPS-treated mice. The cytotoxicity test was used 96 AQueous One solution cell proliferation assay. NO was measured using NO Detection Kit, and the production of pro-inflammatory cytokine was measured using ELISA kit. Findings: As a result, Burdock extract had no cytotoxicity at $10 \mathrm{ug} / \mathrm{mL}$ to $1,000 \mathrm{ug} / \mathrm{mL}$ and significantly inhibited the production of TNF- $\alpha$ as well as IL- 6 and IL- 8 which are pro-inflammatory cytokines. In the RAW 264.7 macrophage cells, Proinflammatory cytokine production inhibitory effects are likely to be diversely utilized as basic physiological activity data and functional materials to demonstrate anti-inflammatory properties of broccoli extract. Improvements/Applications: In conclusion, this study can be used to a basic data to objectively demonstrate the physiological activity of immunological mechanism associated with the anti-inflammatory action of Burdock extract. However, in-depth research on anti-inflammatory is needed.
\end{abstract}

Index Terms

Burdock extract, Anti-inflammatory, Cytokine, TNF- $\alpha$, IL-6, IL-8

\footnotetext{
Corresponding author: Jeong-Sook Park

pk0207@nambu.ac.kr

- Manuscript received October 15, 2021.

- Revised November 10, 2021 ; Accepted December 1, 2021.

- Date of publication December 30, 2021

(c) The Academic Society of Convergence Science Inc.

2619-8363 @ 2021 IJBSA. Personal use is permitted, but republication/redistribution requires IJBSA permission.
} 


\section{INTRODUCTION}

Inflammatory response is the defense mechanism of tissues for internal homeostasis against internal stimuli such as the production of metabolites inside the body through various pathways including external stimuli or bacterial infections[1]. The primary and secondary mediators of various intracellular inflammatory regulators including pro-inflammatory cytokines such as TNF- $\alpha$, IL- 6 , IL-8 and prostagrandin, lysosomal enzymes and free radicals are involved in the inflammatory response[2]. In particular, the transcription factors of inflammatory response are activated by stimuli such as tumor necrosis factor (TNF)- $\alpha$ and lipopolysaccharide (LPS), which are cytokines secreted from macrophages. This induces the expression of inducible nitric oxide synthase and cyclooxygenase- 2 and the production of nitric oxide and prostaglandin E2 causes inflammation[3,4]. The excessive production of NO, a vasodilator, increases inflammatory response, causes septic shock by excessive vasodilation, inhibits wound healing, and damages nerve tissue, and thus causes different diseases in the body[5,6]. Steroids and nonsteroidal antiinflammatory drugs (NSAIDs) used as therapeutic agents for acute and chronic inflammatory diseases are used in various fields, but they are difficult to use for a long time because of serious concerns about side effects[7-9]. Burdock (Arctium lappa L.) is a plant that has been used as a diet for a long time in many countries including Asia[10,11]. Especially, The root part of burdock root has been used as food, and the seed part is diuretic, antipyretic, detoxifying agents have been used in folk medicine. According to experimental evidence, burdock[12-14].

Anti-inflammatory action, scavenging action of free radicals, and antioxidant action were reported in the extract[15]. Antimutagenic and hepatotoxic protective effects were reported in a small number of cases. Studies on the main components of burdock have reported the efficacy of the lignan components arctigenin and acrtiin isolated from burdock fruit[1618]. As such, although studies on the efficacy of burdock extract and its main ingredients are gradually progressing, it is Mechanism of related antiinflammatory action has not been sufficiently reported yet. An experiment was conducted to examine the effect of burdock extract on the inhibition of inflammatory cytokines.

\section{MATERIALS AND METHOD}

\section{A. Experimental Material}

Burdock extract were used by purchasing organic raw materials, and after washing in the shade, about $10 \mathrm{~kg}$ were extracted twice at $50^{\circ} \mathrm{C}$ for 40 hours while shaking $2.5 \mathrm{~kg}$ with methanol. Methanol was obtained by concentration under reduced pressure on a water bath using a rotary vacuum evaporator (EYELA, Tokyo, Japan), which was used as a sample after freezing. Dulbeco's modified eagle medium (DMEM) containing 5\% FBS was used as the cancer cell culture medium, and GIBCO (Grand Island Biological Co., NY, USA) was used for FBS, antibiotics, and trypsinEDTA, The remaining reagents are analytical reagents express, Sigma-Aldrich Co. Ltd (Irvine, UK) reagent was used.

\section{B. RAW 264.7 Cell culture}

RAW264.7 mouse macrophage cell line was ordered from KCLB (Korea Cell Line Bank, Korea) and used for the experiment. DMEM (Dulbecco's Modified Eagle's Medium) medium was used for cell culture and medium containing $12 \%$ FBS and $1.5 \%$ penicillin-streptomycin was used. The macrophages were cultured in a $\mathrm{CO}_{2}$ incubator $\left(37^{\circ} \mathrm{C}, 5 \% \mathrm{CO}{ }_{2}\right)$ and subcultured every other day. Mouse macrophage cells were washed twice with fresh medium and stimulated with $10 \mathrm{ug} / \mathrm{ml}$ LPS.

\section{Cytotoxicity}

Toxicity of Burdock extract to cells was measured using Desai's method [14]. Cytotoxicity assays are to determine the degree of toxicity by measuring the conversion of MTS into formazan by mitochondrial dehydrogenases using MTS assay method. After RAW264.7 macrophage cells were loading at $1.0 \times 105$ cells in 96-well and cultured for 18 hours, Burdock extract was treated at $10 \mu \mathrm{g} / \mathrm{mL}, 100 \mu \mathrm{g} / \mathrm{mL}$ and 1,000 $\mu \mathrm{g} / \mathrm{mL}$ and cultured in CO2 incubator for 24 hours. After $20 \mu \mathrm{l}$ of MTS solution was added 24 hours later and reacted in $\mathrm{CO} 2$ incubator $\left(37^{\circ} \mathrm{C}, \mathrm{CO}_{2} 5 \%\right)$ for 4 hours, the change in absorbance was measured at 450 $\mathrm{nm}$ and then cell viability, which could confirm the cytotoxicity of the control group, was expressed as a percentage.

\section{Measurement of NO}

The NO concentration was measured in the nitrite concentration using Griess reagent system[19]. RAW 264.7 macrophage cells were seeded in a 96-well at a density of $1.0 \times 105$ cells and cultured for 16 hours. The cell were pretreated with Burdock extract 10 
$\mu \mathrm{g} / \mathrm{mL}, 100 \mu \mathrm{g} / \mathrm{mL}$ and $1,000 \mu \mathrm{g} / \mathrm{mL}$ and stimulated with LPS $10 \mathrm{ug} / \mathrm{mL}$ for 24 hour. The same amount of Griess Reagent as the culture medium was added and incubated at room temperature. Absorbance was measured at $540 \mathrm{~nm}$. The concentration of sodium nitrite was used to determine NO concentration in the culture medium.

\section{E. $\quad$ Effect of $T N F-\alpha, I L-6, I L-8$}

RAW264.7 mouse macrophages were seeded on a 96well at a density of $1.0 \times 105$ cells / well and cultured in a $\mathrm{CO} 2$ incubator for 18 hours. Then, Burdock extract was treated with $10 \mu \mathrm{g} / \mathrm{mL}, 100 \mu \mathrm{g} / \mathrm{mL}$ and $1,000 \mu \mathrm{g} / \mathrm{mL}$. After incubation for $24 \mathrm{~h}$ in a CO2 incubator. TNF- $\alpha$, IL-6 and IL-8 proinflammatory cytokines contained in the culture medium, were measured using an ELISA

\section{F. Statistical analysis}

The experimental were determined using the students' t-test, which were calculated as mean \pm standard error (Mean $\pm \mathrm{SE}$ ), were significant when the significance of each group was $p<0.05$. Study Design

\section{RESULTS AND DISCUSSION}

To confirm the cytotoxicity of Burdock extract, which is known to be nontoxic, RAW 264.7 cells were treated with $10 \mathrm{ug} / \mathrm{mL}$ to $1,000 \mathrm{ug} / \mathrm{mL}$ of Burdock extract and then MTS assay was performed. Cell viability was measured at different concentrations. As a result, no toxicity was observed up to a concentration of $1,000 \mathrm{ug} / \mathrm{mL}$. The following experiments were performed at concentrations of 10 $\mu \mathrm{g} / \mathrm{mL}, 100 \mu \mathrm{g} / \mathrm{mL}$ and $1,000 \mu \mathrm{g} / \mathrm{mL}$, which did not affect the cell viability of RAW 264.7 cells. As a result, Burdock extract showed more than $99.6 \pm 5 \%$, $97.9 \pm 3.02 \%$ and $96.0 \pm 2.97 \%$, respectively, at the concentrations of $10 \mu \mathrm{g} / \mathrm{mL}, 100 \mu \mathrm{g} / \mathrm{mL}$ and 1,000 $\mu \mathrm{g} / \mathrm{mL}$, which had no cytotoxicity in figure 1 . The effect of Burdock extract on NO production of RAW 264.7 cells was measured using LPS, which is used as an inflammation inducer in Figure 2. As a result, the concentration of NO was very low in the control group in which only RAW 264.7 cells were cultured, while the concentration of NO in the LPS-treated group was significantly increased. In the experimental group treated with broccoli extract, the production of NO was inhibited in a dose-dependent manner and significant inhibition was observed at $1,000 \mu \mathrm{g} / \mathrm{mL}$. To investigate the effects of Burdock extract on the production of proinflammatory cytokine TNF- $\alpha$, IL-6 and IL-8, RAW 264.7 macrophages were treated with LPS (10 ug / mL) alone, or with LPS and Burdock extract at $10 \mu \mathrm{g} / \mathrm{mL}, 100 \mu \mathrm{g} / \mathrm{mL}$ and $1,000 \mu \mathrm{g} / \mathrm{mL}$. The production of TNF- $\alpha$, IL- 6 and IL- 8 after treatment was investigated. According to the investigation results, the production of TNF- $\alpha$, IL- 6 and IL-8 was inhibited in a dose-dependent manner, TNF- $\alpha$, IL- 8 production in the experimental group treated with $1,00 \mathrm{ug} / \mathrm{Ml}$ and $1,000 \mathrm{ug} / \mathrm{mL}$ was significantly inhibited in Figure 3, 4, 5. MTS assays were performed to measure the toxicity of Burdock extract through LPS stimulation to RAW 264.7 macrophages. There was no cytotoxicity in the control group and the experimental group treated with Burdock extract for 24 hours.

Different inflammatory regulators in cells, as primary and secondary mediators, are involved in inflammation expressed as a defense mechanism in vivo against external infections through various pathways or internal and external stimuli by metabolites in vivo. They are also responsible for different inflammatory diseases such as allergies, atopy, arthritis, heart disease, brain cardiovascular disease and disorders, and cancer [11]. Inflammation is a body defense mechanism, manifesting symptoms and signs in various ways as the most important mechanism in the body defense mechanisms .

The efficacy was demonstrated through an experiment regarding anti-inflammatory properties using various components and preparations extracted from plants. Inflammation involves a variety of mediators, and in particular, pro-inflammatory cytokines produced from cells such as activated lymphocytes and macrophages include TNF- $\alpha$, IL-6 and IL-8. TNF- $\alpha$ plays a key role in regulating innate immune responses, as a major mediator of LPS stimulation. TNF- $\alpha$ is produced from Macrophages and Mast Cell and associated with chronic inflammation in vivo, and it shows intracellular toxicity in tumor cells. In the experimental group treated with Burdock extract to investigate the change in the inhibition of TNF- $\alpha$, IL- 6 and IL- 8 production, it was observed that the production of NO, TNF- $\alpha$, IL6 and IL-8 was inhibited in a dose-dependent manner. According to these study results, Burdock extract has significant anti-inflammatory properties due to proinflammatory Cytokine TNF- $\alpha$ production inhibitory effects in LPS-induced inflammatory model[20.21].

\section{Conclusion}

To confirm the cytotoxicity of Burdock extract, which is known to be nontoxic, RAW 264.7 cells were treated with $10 \mathrm{ug} / \mathrm{mL}$ to $1,000 \mathrm{ug} / \mathrm{mL}$ of Burdock 
extract and then MTS assay was performed. Cell viability was measured at different concentrations[22]. In conclusion, this study can be used as a basic data to objectively demonstrate the physiological activity of immunological mechanism associated with the antiinflammatory action of Burdock extract, but it is necessary to conduct in-depth studies on antiinflammation.

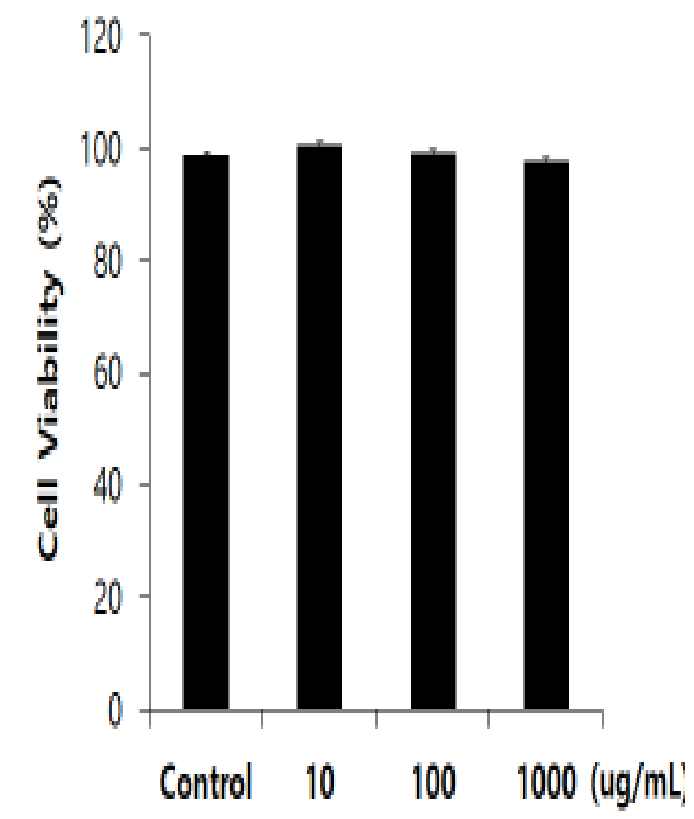

Fig. 1. Effects of Burdock extract on the cell viability of RAW264.7 cells.

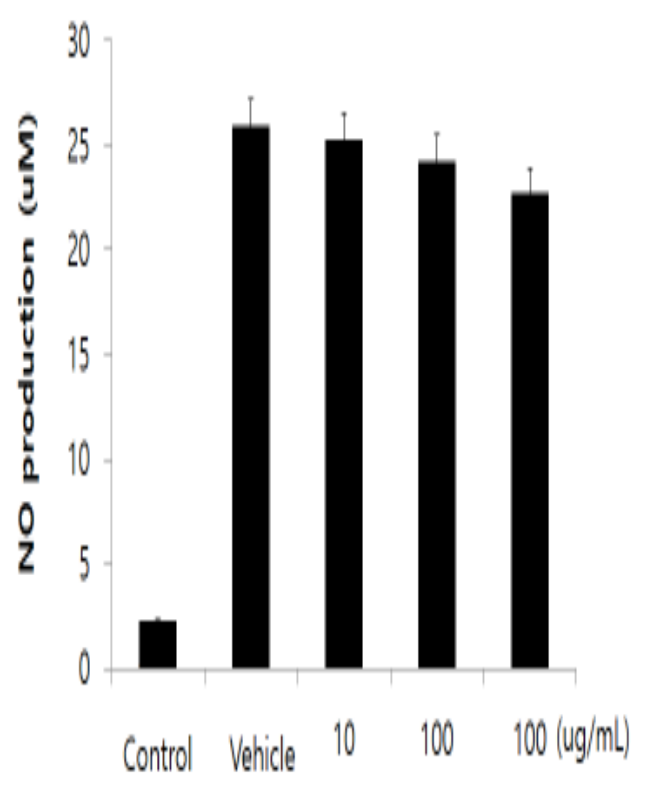

Fig. 2. Effects of Burdock extract on Inhibition of NO production in LPS-stimulated RAW 264.7 cells.

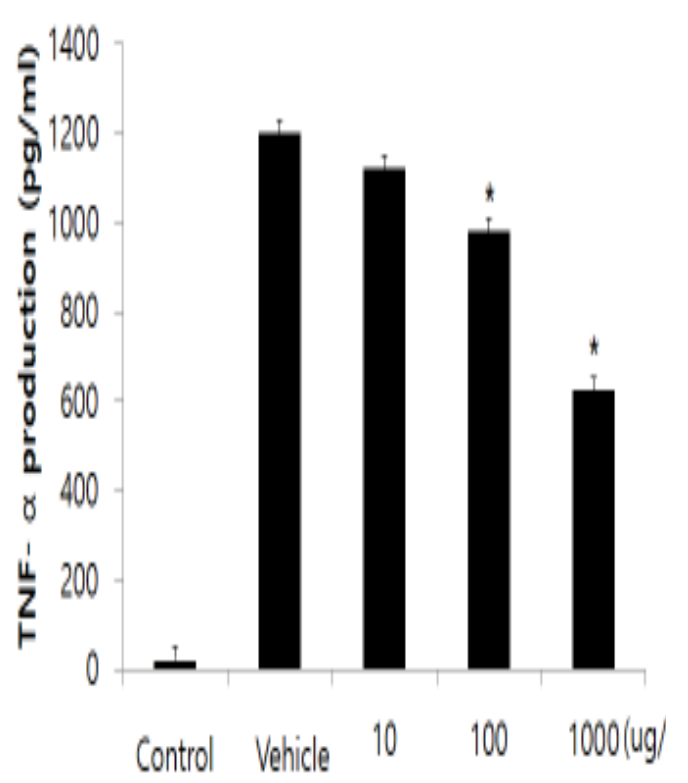

Fig. 3. Effects of Burdock extract on Inhibition of TNF- $\alpha$ production in LPS-stimulated RAW 264.7 cells. 


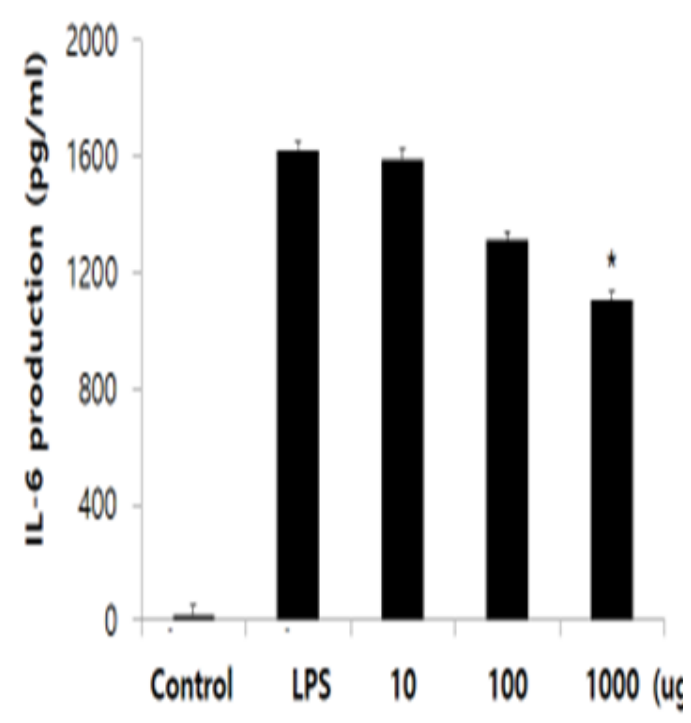

Fig. 4. Effects of Burdock extract on Inhibition of IL6 production in LPS-stimulated RAW 264.7 cells.

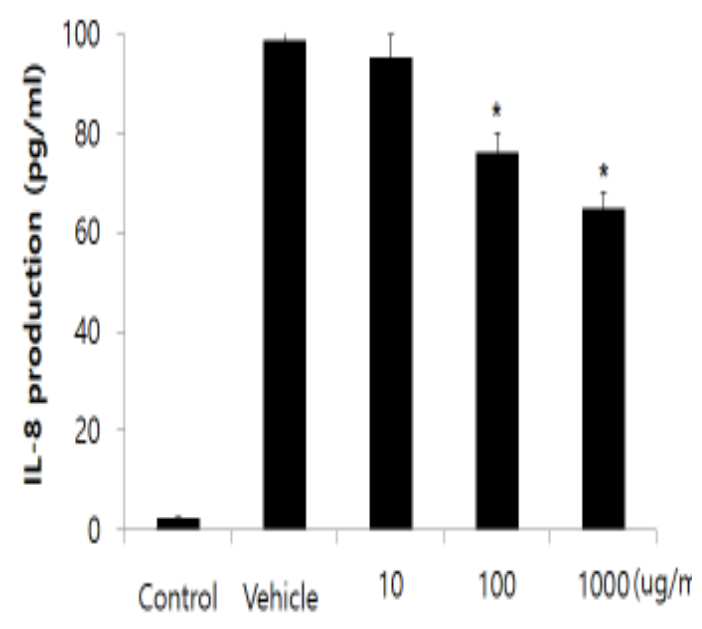

Fig. 5. Effects of Burdock extract on Inhibition of IL8 production in LPS-stimulated RAW 264.7 cells.

\section{REFERENCES}

[1] Rocca, B., FitzGerald, G. A. Cyclooxygenases and Prostaglandins Shaping up the Immune Response, Int. Immunopharmacol, 2002; 2, 603-630.

[2] MacSween, R., Whaley, K. Muir's Textbook of Pathology, 13th ed. London: Edward Arnold.

[3] Seo, S. J., Cho,i H. G., Chung, H. J., Hong, C. K. Time course of expression of mRNA of inducible nitric oxide synthase and generation of nitric oxide by ultraviolet B in keratinocyte cell lines, Br .J. Dermatol, 2002; 147, 655-662.

[4] Shew, R. L., Papka, R. E., McNeill, D. L., Yee, J. A. NADPH-diaphorase-positive nerves and the role of nitric oxide in CGRP relaxation of uterine contraction, Peptides, 1993; 14, 637-641.

[5] Weller, R. Nitric oxide - a newly discovered chemical transmitter in human skin, Br J. Dermatol, 1997; 137, 665-672.

[6] Kwqamata, H., Ochiai, H., Mantani, N., terasawa, K. Enhanced expression of inducible nitric oxide synthase by Juzen-taiho-to in LPS activated RAW 264.7 cells, a murine macrophage cell line, Am J Chin Med,2000; 28, 217-226.

[7] Masaki, M., Matsushita, M., Wakitani, K. Inhibitory effect of JTE-522, a novel prostaglandin H synthase-2 inhibitor, on adjuvant-induced arthritis and bone changes in rats, Inflamm. Res, 1998; 47, 187-192.

[8] Gleich, G. J. Mechanisms of eosinophil associated inflammation, J.Allergy Clin. Immunol, 2000; 105, 651-663.

[9] Park, J. S., Kim, M. H. Anti-Inflammatory Effects of Rice Bran Ethanol Extract in Murine Macrophage RAW 264.7 Cells, Yakhak Hoeji,2011; 6, 456-461.

[10] Fuchigami, M., Y. Kishigami and A. Sasaki. Pectic polysaccharides in edible burdock root. J. Home Economics Japan 1990; 41:947-962.

[11] Park, S.Y., S.S. Hong, X. Han, J.S. Hwang, D. Lee, J.S. Ro and B.Y. Hwang. Lignans from Arctium lappa and their inhibition of LPS-induced nitric oxide production. Chem. Pharm. Bull. 2007; 55:150-152.

[12] Lin, C.C., J.M. Lu, J.J. Yang, S.C. Chuang and T. Ujiie. 1996. Anti-inflammatory and radical scavenge effects of Arctium lappa. American J. Chin. Med. 1996; 24:127-137

[13] Kou, X., S. Qi, W. Dai, L. Luo and Z. Yin. Arctigenin inhibits lipopolysaccharide-induced iNOS expression in RAW264.7 cells through suppressing JAK-STAT signal pathway. Int. Immunopharmacol. 2011; 11(8):1095-102

[14] Chen, F.A., A.B. Wu and C.Y. Chen. The influence of different treatment on the free radical scavenging activity of burdock and variations of its active components. Food Chem. 2004; 86:479-484 
[15] Maruta, Y., J. Kawabata and R. Niki.Antioxidative caffeoylquinic acid derivatives in the roots of burdock (Arctium lappa L.). J. Agric. Food Chem. 1995; 43:2592-2595.

[16] Lee, M.Y., S.L. Shin, S.H. Park, N.R. Kim, Y.D. Chang and C.H. Lee. Development of optimal cultivation conditions and analysis of antioxidant activities of Arctium lappa sprout vegetables. J. Korean Plant Res. 2009; 22(4): 281-363

[17] Morita KY, Y. Nishijima and T. Kada. Chemical nature of a desmutagenic factor from burdock (Arctium lappa L.). Agric. Biol. Chem.1985; 49:925-932

[18] Lin, S.C., C.H. Lin, C.C. Lin, Y.H. Lin, C.F. Chen, J.C. Chen and L.Y. Wang. Hepatoprotective effects of Arctium lappa L. on liver injuries induced by chronic ethanol consumption and potentiated by carbon tetrachloride tetrachloride. J. Biomed. Sci. 2002; 9:401-409

[19] Wang, S., Chen, Y., He, D., He, L., Yang, Y., Chen, J., Wang, X. Inhibition of vascular smooth muscl cell proliferation by serum from rats treated orally with Gastrodia and Uncaria decoction, a traditional Chinese formulation, J. Ethnopharmacol,2007; 114, 458-62.

[20] Park, M. Y., Yoon, M. K., Kwak, J. H. (2014)Antimicrobial and Antioxidant Activities in Different Parts and Cultivars of Broccoli. Kor. J. Hort. Sci. Technol.2014; 32(3):408414.

[21] Kim, M.R., K.J. Lee, J.H. Kim, and D.E. Sok. Determination of sulforaphane in cruciferous vegetables by SIM. Korean J. Food Sci. Technol. 1997; 29:882-887.

[22] Stangeland, T., S.F. Remberg, and K.A. Lye. Total antioxidant activity in 35 Ugandan fruits and vegetables. Food Chem.2009; 113: 85-91 